Metal lons in Biological Systems, A. Sigel and H. Sigel, eds., Marcel Dekker Inc.: New York, Vol. 42, Ch 2, 2004.

\title{
Luminescent Lanthanide Probes as Diagnostic and Therapeutic Tools
}

\author{
Jean-Claude G. Bünzli \\ Swiss Federal Institute of Technology, \\ Institute of Molecular and Biological Chemistry, \\ Laboratory of Lanthanide Supramolecular Chemistry, \\ BCH 1402, CH-1015 Lausanne, Switzerland
}

1. LANTHANIDE-BASED LUMINESCENT PROBES: WHY? 40

1.1. Basic Properties of Lanthanide Trivalent Ions 40

1.2. Lanthanide Luminescent Probes in Biological Systems 43

2. DESIGNING A LANTHANIDE-BASED

LUMINESCENT PROBE

2.1. Photophysical Aspects 44

2.1.1. Optimizing Energy Transfer Processes 47

2.1.2. Minimizing Non-radiative Processes 48

2.1.3. Energy Back Transfer 49

2.2. Chemical Aspects 50

2.2.1. Thermodynamic Considerations 50

2.2.2. Kinetics 51

2.2.3. Synthetic Strategies 52

2.3. Biochemical Aspects 53

2.4. Methododical Aspects: Time-Resolved Luminescence (TRS) 56

3. APPLICATIONS IN MEDICAL DIAGNOSIS 57 
3.1. Heterogenous versus Homogenous Immunoassays 57

3.2. Nucleic Acid and DNA Hybridization Probes 58

3.3. Clinical Examples 60

3.3.1. Human Immunogrobulin $\mathrm{I}_{\mathrm{g}} \mathrm{E} \quad 60$

3.3.2. $\alpha$-Fetoprotein 61

3.3.3. Herpes Simplex Virus 62

3.3.4. Prostate Specific Antigen 62

3.3.5. Children Diabetes 63

3.3.6. Determination of Grepafloxacin 69

3.4. Imaging Techniques for Enhanced Detection of Cancerous Cells

4. USE OF LANTHANIDE COMPLEXES

IN PHOTODYNAMIC THERAPIES 65

4.1. Principle of Photodynamic Therapy 66

4.2. Lanthanide Texaphyrins 68

4.3. Clinical Applications $\quad 68$

4.3.1. Cancer Phototherapy 68

4.3.2. Photoangioplasty 69

4.3.3. Age-Related Macular Degeneration $\quad 70$

5. CONCLUDING REMARKS 70

ACKNOWLEDGMENTS $\quad 71$

ABBREVIATIONS $\quad 71$

REFERENCES $\quad 72$

\section{LANTHANIDE-BASED LUMINESCENT PROBES: WHY?}

\subsection{Basic Properties of Lanthanide Trivalent lons}

The lanthanides, or $4 \mathrm{f}$ elements, which extend from lanthanum (atomic number 57) through lutetium (71) form essentially trivalent $\mathrm{Ln}^{\mathrm{III}}$ ions in aqueous solution with an electronic structure consisting of a xenon core and $4 \mathrm{f}$ valence electrons, $[\mathrm{Xe}] 4 \mathrm{f}^{\mathrm{n}}$. That is, the valence electrons are shielded from external interactions, henceforth, the characteristic chemical, spectroscopic and magnetic properties of these ions (Table 1). The series is termed rare earths when scandium and yttrium are added to it. 
Chemically, they are hard cations, binding preferentially oxygen and nitrogen. Their ionic radii are quite comparable to those of calcium and zinc. Moreover, they display Lewis acid properties which make them useful in the hydrolytic cleavage of phosphor-diester bonds of DNA which, otherwise, is extremely resistant to hydrolysis; cleavage of DNA is an essential step in developing gene therapy.

Another consequence of the shielding of the $4 \mathrm{f}$ orbitals is that the selection rules forbidding $\mathrm{f}-\mathrm{f}$ transitions are only weakly relaxed and these transitions are faint and keep their atomic nature, i.e., they appear as sharp and weak lines, the energy of which is not much influenced by the surroundings of the metal ion, except for the crystal-field induced fine structure. This apparent disadvantage may be turned into a serious asset since these lines are easily recognizable and very useful for the development of valuable luminescent probes with wide potential applications, ranging from solid state physics to medical diagnosis. For the same reasons, magnetic properties are not much influenced by the nature of the inner coordination sphere and remain essentially those of the free ions; magnetic interactions between $4 \mathrm{f}$ and $3 \mathrm{~d}$ or $4 \mathrm{f}$ ions occur only when the metal-metal distance is short (smaller than $4 \AA$ ) and are faint. Several applications take advantage of the large paramagnetic susceptibility exhibited by many $\mathrm{Ln}^{\mathrm{III}}$ ions. For instance, Er ${ }^{\mathrm{III}}$ is useful in the separation and isolation of particles (e.g., bacterial or eukaryotic cells), and $\mathrm{Gd}^{\mathrm{III}}$ is the core constituent of several contrasting agents for the enhancement of medical images recorded by magnetic resonance [1].

Luminescence has played an essential role in the discovery of the rareearth elements and in their early uses, particularly as inorganic phosphors. The first report on the lanthanide-centered luminescence of a coordination compound was published in 1942 by Weissman [2]. Using the sun as a source of light, Weissman noted that absorption of radiation with wavelengths in the range 320 to $440 \mathrm{~nm}$ by the organic part of several $\mathrm{Eu}^{\mathrm{III}}$ complexes resulted in the characteristic line luminescence from the f-f transitions of trivalent europium. Studying several anionic chelating agents such as $\beta$-diketonates, benzoates, salicylates or picrates, he observed that the efficiency of excitation varies greatly with the nature of the compounds, as well as with the temperature and the solvent, and speculated that in some cases a quantum yield of unity was obtained at low temperature. 


\section{TABLE 1}

Basic properties of trivalent rare earth ions and of $\mathrm{Ca}^{\mathrm{II}}$ : electronic structure, intrinsic color (all colors mentioned are pale), magnetic moment in Bohr magnetons, ionic radii for coordination numbers 9 and 12, and hydration enthalpy at $298 \mathrm{~K}\left(\mathrm{kJmol}^{-1}\right)$. Data are taken from [3]

\begin{tabular}{lllllll}
\hline Ion & El. Struct. & Color & $\mu(\mathrm{B} . \mathrm{M})$. & $r_{\mathrm{i}}(9) / \AA$ & $r_{\mathrm{i}}(12) / \AA$ & $-\Delta H_{\mathrm{h}}{ }^{0}$ \\
\hline $\mathrm{Ca}$ & {$[\mathrm{Ar}]$} & colorless & 0 & 1.18 & $\mathrm{n} . \mathrm{a}$. & 1585 \\
$\mathrm{Sc}$ & {$[\mathrm{Ar}]$} & colorless & 0 & 0.93 & 1.06 & $3884 \mathrm{~b})$ \\
$\mathrm{Y}$ & {$[\mathrm{Kr}]$} & colorless & 0 & 1.08 & 1.22 & 3640 \\
$\mathrm{La}$ & {$[\mathrm{Xe}]$} & colorless & 0 & 1.22 & 1.36 & 3326 \\
$\mathrm{Ce}$ & {$[\mathrm{Xe}] 4 \mathrm{f}^{1}$} & colorless & 2.56 & 1.20 & 1.34 & 3380 \\
$\mathrm{Pr}$ & {$[\mathrm{Xe}] 4 \mathrm{f}^{2}$} & green & 3.62 & 1.18 & 1.32 & 3421 \\
$\mathrm{Nd}$ & {$[\mathrm{Xe}] 4 \mathrm{f}^{3}$} & violet & 3.68 & 1.16 & 1.30 & 3454 \\
$\mathrm{Pm}$ & {$[\mathrm{Xe}] 4 \mathrm{f}^{4}$} & rose & 2.83 & 1.14 & 1.28 & 3482 \\
$\mathrm{Sm}$ & {$[\mathrm{Xe}] 4 \mathrm{f}^{5}$} & cream & 1.65 & 1.13 & 1.27 & 3512 \\
$\mathrm{Eu}$ & {$[\mathrm{Xe}] 4 \mathrm{f}^{6}$} & pale pink & 3.51 & 1.12 & 1.25 & 3538 \\
$\mathrm{Gd}$ & {$[\mathrm{Xe}] 4 \mathrm{f}^{7}$} & colorless & 7.94 & 1.11 & 1.24 & 3567 \\
$\mathrm{~Tb}$ & {$[\mathrm{Xe}] 4 \mathrm{f}^{8}$} & colorless & 9.7 & 1.10 & 1.23 & 3600 \\
$\mathrm{Dy}$ & {$[\mathrm{Xe}] 4 \mathrm{f}^{9}$} & cream & 10.6 & 1.08 & 1.22 & 3634 \\
$\mathrm{Ho}$ & {$[\mathrm{Xe}] 4 \mathrm{f}^{10}$} & yellow & 10.6 & 1.07 & 1.21 & 3663 \\
$\mathrm{Er}$ & {$[\mathrm{Xe}] 4 \mathrm{f}^{11}$} & pink & 9.6 & 1.06 & 1.19 & 3692 \\
$\mathrm{Tm}$ & {$[\mathrm{Xe}] 4 \mathrm{f}^{12}$} & green & 7.6 & 1.05 & 1.18 & 3717 \\
$\mathrm{Yb}$ & {$[\mathrm{Xe}] 4 \mathrm{f}^{13}$} & colorless & 4.5 & 1.04 & 1.17 & 3740 \\
$\mathrm{Lu}$ & {$[\mathrm{Xe}] 4 \mathrm{f}^{14}$} & colorless & 0 & 1.03 & 1.16 & 3759 \\
\hline & & & & & & \\
\hline
\end{tabular}

The intermolecular energy transfer process between an organic ligand and a luminescent metal ion is presently designated as the "antenna effect". The discovery stirred interest but no immediate application was found and, moreover, coordination chemistry of the $\mathrm{Ln}^{\mathrm{III}}$ ions did not develop much until the 1960's when it was finally recognized that these ions usually display a large coordination number $[3,4]$, which inevitably influences the 
design of adequate receptors. The excited states of luminescent $\mathrm{Ln}^{\mathrm{III}}$ ions are populated by a fast intramolecular energy transfer process from a triplet state of the ligand (itself populated from the singlet state by intersystem crossing), as demonstrated for the first time by Crosby et al. [5]. Estimates for the transfer rate range between $10^{6}$ to $10^{9} \mathrm{~s}^{-1}$.

\subsection{Lanthanide Luminescent Probes in Biological Systems}

Luminescence is a highly sensitive analytical method since nowadays single molecule detection is becoming common and henceforth, its interest for medical analysis and diagnosis. However, biological material is highly complex and usually bears numerous fluorescent groups. Therefore, luminescent stains based on organic dye molecules, although highly sensitive, are not completely adequate in view of the difficulty in separating the fluorescence of the stain from that of the sample. On the other hand, lanthanide ions are ideal luminescent probes for biological systems because their line-like emission bands are easily recognizable, well separated from the broad band fluorescence emission from organic moieties and, moreover, light emission by these metal ions is a phosphorescence process. The excited states are therefore long-lived, allowing, in addition, time-resolved separation of the $\mathrm{Ln}^{\mathrm{III}}$ ion phosphorescence from the fluorescence of the biological sample. As a consequence, the luminescent $\mathrm{Ln}^{\mathrm{III}}$ ions seem to be ideally suited for becoming widely used probes in biological systems. There are however two problems to overcome. The first one is related to the need of going through a sensitisation process of the metal ion luminescence via the antenna effect (vide supra). Secondly, $\mathrm{Ln}^{\mathrm{III}}$ ions are toxic [6]. There are known to have bacteriological effects, to easily replace calcium and zinc (and possibly other biologically relevant metal ions), and to kill cells. Although the latter property may be turned into an advantage, for instance for curing cancer, it is not welcome for diagnostic tools. The $\mathrm{Ln}^{\mathrm{III}}$ ions have therefore to be inserted into highly stable molecular edifices, both from the thermodynamic and kinetic viewpoints. This represents a challenging task for the synthetic chemists, which now begins to find appealing solutions.

Historically, the first application of luminescent $\mathrm{Ln}^{\mathrm{III}}$ ions for the analysis of biological systems has been the investigation of metal ion sites in 
proteins, mainly calcium-binding proteins. In these studies, $\mathrm{Eu}^{\mathrm{III}}$ and $\mathrm{Tb}^{\mathrm{III}}$ act as replacement probes and the number of metal ion sites, their chemical composition (especially with respect to the number of coordinated water molecules), as well as their mutual distances have been determined with good accuracy. This type of analysis continues to attract interest, as described in recent review articles $[7,8]$.

A big stimulus arose in the mid 1980's when a small Finnish company, Wallac Oy from Turku, marketed bioassays based on timeresolved luminescence of $\mathrm{Eu}^{\mathrm{III}}$ [9]. These fluoroimmunoassays (FIA) rely on antibodies labelled with lanthanide chelates which specifically react with the targeted antigens. Since then, many research groups have been developing carefully engineered organic molecules able to encapsulate the $\mathrm{Ln}^{\mathrm{III}}$ ions and to enhance their luminescent properties. This growing interest for molecular devices built from organic molecules is also motivated by the development of other recent biomedical applications such as DNA and RNA labelling, nucleic acid hybridization assays [10], and by the design of luminescent responsive systems for in vitro trace analysis [11].

In the following sections, the discussion focuses on lanthanide-containing diagnostic tools for biology and medicine, as well as on some potential therapeutical applications. It is not intended to present a comprehensive review of these fields but, rather, to exemplify some of the main applications.

\section{DESIGNING A LANTHANIDE-BASED LUMINESCENT PROBE}

\subsection{Photophysical Aspects}

Which ions are of interest in the reviewed field? In fact, most $\mathrm{Ln}^{\mathrm{III}}$ ions are luminescent, but medical applications require the use of organic complexes in aqueous solution and at physiological $\mathrm{pH}$ of 7.4, which severely limits the choice of potentially interesting ions. Indeed, the emission intensity is qualitatively inversely proportional to the energy gap between the lowest lying excited (emissive) state of the metal ion and its ground manifold. Emission from higher excited states is rarely seen in solution. 


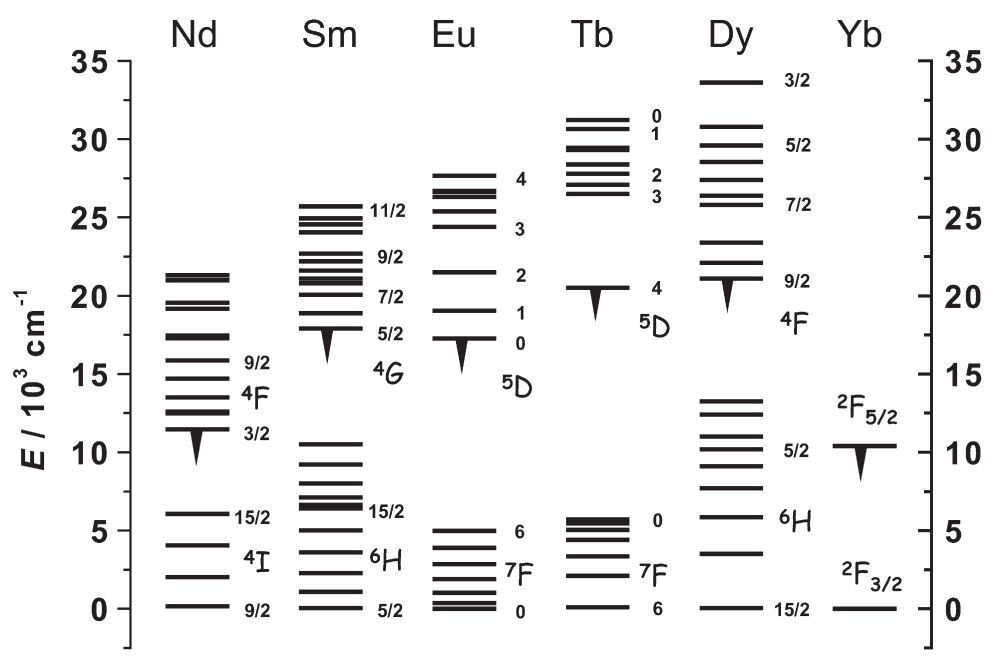

FIG. 1. Partial energy diagrams of some luminescent $\mathrm{Ln}^{\mathrm{III}}$ ions. Luminescent states are indicated by down-pointing arrows.

When the gap is small, it can be easily bridged by nonradiative processes involving vibrational levels, which are numerous in organic complexes. Taking this requirement into account, the best ions are therefore $\mathrm{Eu}^{\mathrm{III}}$, Gd ${ }^{\mathrm{III}}$, and $\mathrm{Tb}^{\mathrm{III}}$, with energy gaps around 12150,32000 , and $14800 \mathrm{~cm}^{-1}$, respectively (FIG. 1).

However, Gd ${ }^{\mathrm{III}}$ emits in the UV and is not much useful since its luminescence will interfere with either luminescence or absorption processes in the organic part of the complex molecule. Developments of dual fluoroimmunoassays has also stirred interest for the luminescence of $\mathrm{Sm}^{\mathrm{III}}$ (gap $\left.7400 \mathrm{~cm}^{-1}\right)$ and DyIII $\left(7850 \mathrm{~cm}^{-1}\right)$, as well as, more recently, the advent of chiral luminescent probes emitting in the far infrared has stimulated attention to $\mathrm{Nd}$ III $\left(5500 \mathrm{~cm}^{-1}\right)$ and $\mathrm{Yb}^{\mathrm{III}}\left(10400 \mathrm{~cm}^{-1}\right)$, despite their very low quantum yields.

As noted above, $\mathrm{f}-\mathrm{f}$ transitions are very weak, so that direct excitation of the $\mathrm{Ln}{ }^{\mathrm{III}}$ ions rarely yields highly luminescent materials. Indirect excitation (called sensitization or antenna effect) has to be used and proceeds in three steps. First, light is absorbed by the immediate environment of the 
$\mathrm{Ln}^{\mathrm{III}}$ ion through the attached organic ligands (chromophores). Energy is then transferred onto the metal ion mainly through the ligand triplet state and, finally, the metal ion emits light. This process results in light-converting devices since usually UV or blue light is absorbed while green $(\mathrm{Tb})$, yellow (Dy), orange $(\mathrm{Sm})$, red $(\mathrm{Eu})$ or near IR $(\mathrm{Nd}, \mathrm{Yb})$ light is given off. A simplified scheme of these energy transfer processes is given in Figure 2. As seen from this schematic diagram, more than ten energy migration paths are possible, in general, each characterized by a rate constant. For EuIII and other easily reducible lanthanide ions, metal-to-ligand charge transfer states must be considered, especially if they lie below $25,000 \mathrm{~cm}^{-1}$ since they deactivate the metal excited state, which adds more energy migration paths to the scheme. Moreover, the picture is not exhaustive, since we have not taken into account intermolecular processes which may gain in importance either in solids where $\mathrm{Ln}^{\mathrm{III}}$ ions lie at relatively short distances so that energy can migrate from one metallic site to the other, or in solution where collisions with other molecules may result either in beneficial energy transfers or in the deactivation of the metal ion excited state. Polymeric structures containing both luminescent and non-luminescent $\mathrm{Ln}^{\mathrm{III}}$ ions may

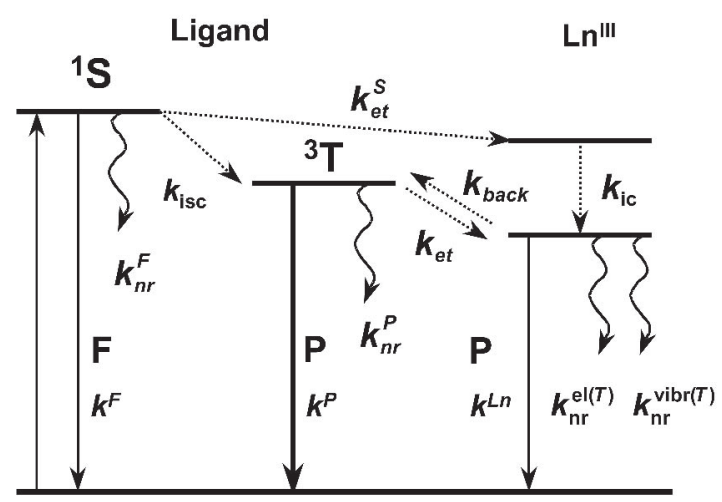

FIG. 2. Simplified diagram showing the energy migration paths in a $\mathrm{Ln}^{\mathrm{III}}$ complex $\left({ }^{1} \mathrm{~S}=\right.$ singlet state, ${ }^{3} \mathrm{~T}=$ triplet state, $\mathrm{F}=$ fluorescence, $\mathrm{P}=$ phosphorescence, isc = intersystem crossing, $\mathrm{nr}=$ nonradiative, $\mathrm{ic}=$ internal conversion, et $=$ energy transfer, back $=$ back transfer, $T=$ temperature-dependent, $\mathrm{el}=$ electronic, vibr $=$ vibrational. 
also lead to enhanced luminescent properties through energy transfer from the non-luminescent centers onto the luminescent ones.

\subsubsection{Optimising Energy Transfer Processes}

In absence of good predictive theoretical models, experimentalists have to rely on rules of thumb and several of them have been established for given series of $\mathrm{Eu}^{\mathrm{III}}$ and $\mathrm{Tb}^{\mathrm{III}}$ compounds. Two main processes have to be optimized: the intersystem crossing $\left(k_{\mathrm{isc}}\right)$ and the ${ }^{3} \pi \pi^{*}$-to-metal energy transfer $\left(k_{\mathrm{et}}\right)$. Consequently, energy losses have to be avoided at all stages: light emission or non-radiative de-excitation from the ligand $\left(k^{\mathrm{F}}, \mathrm{k}_{n r}^{\mathrm{F}}, \mathrm{k}^{\mathrm{P}}\right.$, and $\mathrm{k}_{n r}^{\mathrm{P}}$ ), as well as non-radiative de-excitation of the metal ion luminescent state $\left(\mathrm{k}_{n r}^{\mathrm{i}}\right)$.

From organic photochemistry data, it is known that efficient isc takes place when $\Delta E\left({ }^{1} \pi \pi^{*}-3 \pi \pi^{*}\right)$ is around $5000 \mathrm{~cm}^{-1}$.

With respect to the triplet-to-metal ion transfer, two series of compounds have been studied in detail and are often referred to: (i) $\mathrm{Eu}^{\mathrm{III}}$ and $\mathrm{Tb}^{\mathrm{III}}$ polyaminocarboxylates for which the quantum yield upon ligand excitation becomes sizeable when $\Delta E\left({ }^{3} \pi \pi^{*}-5 D_{J}\right)>2000 \mathrm{~cm}^{-1}$ [12]. When this gap is smaller, energy back transfer can occur $\left(k_{b a c k}\right)$, and (ii) complexes with triphenylene-substituted calix[4]arenes for which the ideal $\Delta E\left({ }^{3} \pi \pi^{*}-5 \mathrm{D}_{\mathrm{J}}\right)$ gap is around $3500 \mathrm{~cm}^{-1}$ [13]. Note that $E\left({ }^{3} \pi \pi^{*}\right)$ refers to the zero-phonon transition.

These considerations are somewhat oversimplified. The mechanism of the ligand-to-metal energy transfer has often a dipole-dipole nature. The overlap integral $J$ between the emission spectrum of the donor $\left({ }^{3} \pi \pi^{*}\right)$ state and the absorption spectrum of the acceptor state has also to be taken into consideration. This quantity may vary considerably depending upon the width of the ${ }^{3} \pi \pi^{*}$ emission spectrum and, also, upon the orientation of the chromophore with respect to the $\mathrm{Ln}^{\mathrm{III}}$ ion. Moreover, the distance between the chromophore and the $\mathrm{Ln}^{\mathrm{III}}$ ion is crucial since the dipole-dipole transfer fades off as $\left(r_{\mathrm{DA}}\right)^{-6}$.

The overall luminescence quantum yield of the metal-centered luminescence upon excitation through the ligand states can be expressed as:

$$
Q_{\mathrm{tot}}=\eta_{\mathrm{isc}} \cdot \eta_{\mathrm{e}} \cdot Q_{\mathrm{Ln}}
$$


where $\eta_{\text {isc }}$ is the yield of the intersystem crossing to the triplet state, $\eta_{\mathrm{et}}$ the efficiency of the ligand-to- $\mathrm{Ln}^{\mathrm{III}}$ energy transfer; $Q_{\mathrm{Ln}}$ is expressed as:

$$
Q_{\mathrm{Ln}}=\frac{k_{r}}{k_{r}+k_{n r}}=\frac{\tau_{o b s}}{\tau_{R}}
$$

where $k$ 's are deactivation rate constants (radiative and non-radiative) and $\tau$ 's are lifetimes of the metal excited level. In the particular case of EuII, the radiative lifetime can be estimated by:

$$
\frac{1}{\tau_{R}}=14.65 \cdot n^{3} \cdot\left(\frac{I_{t o t}}{I_{M D}}\right) \quad\left[\mathrm{s}^{-1}\right]
$$

$n$ is the refractive index of the solution, $I_{t o t}$ the total integrated emission intensity, and $I_{\mathrm{MD}}$ the integrated intensity of the magnetic dipole transition ${ }^{5} \mathrm{D}_{0} \rightarrow{ }^{7} \mathrm{~F}_{1}$. Therefore, a measurement of $Q_{\mathrm{Ln}}, \tau_{\mathrm{obs}}$ and the entire emission spectrum (580-820 nm, ${ }^{5} \mathrm{D}_{0} \rightarrow{ }^{7} \mathrm{~F}_{\mathrm{J}}$ transitions with $\left.\mathrm{J}=0-6\right)$ allows one to determine $\eta_{\mathrm{et}}$.

\subsubsection{Minimizing Non-radiative Processes}

Two types of processes intervene, vibrational and electronic, and both are temperature-dependent. The most effective vibrations for deactivating an excited state are those with high energy, especially when one donor atom involved in the vibration is directly connected to the metal ion via a chemical bond. The de-excitation effectiveness is inversely proportional to the number of vibrational quanta required to match the gap between the lowest sub-level of the excited state and the highest sublevel of the ground state. Phononassisted deactivation has been taken advantage of to determine the number of water molecules coordinated onto $\mathrm{Sm}^{\mathrm{III}}$, Eu${ }^{\mathrm{III}}$, Tb ${ }^{\mathrm{III}}$, DyIII, and $\mathrm{Yb}^{\mathrm{III}}$ ions by measuring the lifetime $\tau$ of the excited levels both in water and deuterated water (for a summary, see [14]). Assuming that nonradiative processes other than the quenching by high energy vibrations are the same in both cases, and that water exchange is fast, the difference in the measured rate constants will be proportional to the number of coordinated $\mathrm{OH}$ oscillators, that is to the number $q$ of coordinated water molecules:

$$
\Delta k_{\text {obs }}=k_{\text {obs }}\left(\mathrm{H}_{2} \mathrm{O}\right)-k_{\text {obs }}\left(\mathrm{D}_{2} \mathrm{O}\right)=\tau^{-1}\left(\mathrm{H}_{2} \mathrm{O}\right)-\tau^{-1}\left(\mathrm{D}_{2} \mathrm{O}\right) \propto q
$$


Calibrating the relationship with compounds for which the number of coordinated water molecules is known (for instance by X-ray crystallography, or by NMR) allows one to determine the proportionality constant. The main hypothesis made is that each bound $\mathrm{OH}$ oscillator contributes equally to the quenching process, which in turn implies that the $\mathrm{Ln}-\mathrm{OH}$ distance is the same in compounds in which both only a few or many water molecules are bound into the first coordination sphere of the metal ion. The assumption seems to hold fairly well and accuracy of about $\pm 10 \%$ on the number of water molecules can be reached. The accuracy depends on the number of corrective factors taken into consideration (for instance second sphere interactions) and on the quality of the calibration for a given series of compounds.

Electronic deactivation processes are also very important. When a molecule is excited by absorption of light, its electron donor or electron acceptor properties are modified. For instance, it may become a more powerful electron donor. Consequently, an electron transfer, not feasible in the ground state, may occur upon photo-excitation. The phenomenon is known as photo-induced electron transfer (PET). Although it often prevents the design of highly luminescent stains, it may prove useful in the planning of analytical methods or in the development of signalling processes and molecular logic gates [15]. When such PET processes involve the direct reduction (or oxidation) of a metal ion, one often speaks of ligand-to-metal charge transfer (LMCT), or of metal-to-ligand charge transfer (MLCT). In view of the redox potentials of the $\mathrm{Ln}^{\text {III }}$ ions, only $\mathrm{Sm}^{\mathrm{III}}$, $\mathrm{Eu}^{\mathrm{III}}$, and $\mathrm{Yb}^{\mathrm{III}}$ are amenable to reductive LMCT processes, while MLCT's can essentially occur with Ce $\mathrm{e}^{\mathrm{III}}$ and $\mathrm{Tb}^{\mathrm{III}}$. In any case, these processes, which are usually very fast, efficiently compete with the $\mathrm{Ln}^{\mathrm{III}}{ }^{\mathrm{*}}$ deactivation and quench the luminescence.

\subsubsection{Energy Back Transfer}

When both the excited metal ion and the ligand triplet levels lie close in energy, energy from the former can flow back onto the ligand. This process is often assisted by vibrations and the temperature dependence of the lifetime can be described by an Arrhenius-type equation: 


$$
\ln \left(\tau^{-1}-\tau_{0}^{-1}\right)=A+E_{\mathrm{A}} / R T
$$

where $\tau$ is the actual lifetime, $\tau_{0}$ the lifetime in absence of back transfer (frequently taken as the lifetime at very low temperature), while $E_{\mathrm{A}}$ is the activation energy of the process which often matches a vibration of the molecule under study.

\subsection{Chemical Aspects}

The ionic radii of $\mathrm{Ln}{ }^{\mathrm{III}}$ ions sustain a rather smooth decline (disregarding small, second order effects) with increasing atomic number (Table 1). As the nucleus charge increases, it exerts a greater electrostatic attraction over the $4 \mathrm{f}$ electrons, henceforth the so-called "lanthanide contraction". It is noteworthy that the ionic radii strongly depend upon the coordination number (Table 1), which makes the $\mathrm{Ln}^{\mathrm{III}}$ ions highly adaptable to many coordination environments. Indeed, the difference in ionic radius between coordination numbers 6 and 12 amounts to $0.3 \AA$ while it is only $0.16 \AA$ between $\mathrm{La}$ and $\mathrm{Lu}$ and $\approx 0.015 \AA$ between two consecutive ions. Moreover, the spherical trivalent lanthanides are labile and stereochemically versatile metal ions, so that a rational control of their coordination sphere entirely relies on conformational restriction of the receptors. This poses a real challenge to synthetic chemists if a given $\mathrm{Ln}^{\mathrm{III}}$ ion were to be introduced specifically into a functional edifice.

\subsubsection{Thermodynamic Considerations}

From the thermodynamic viewpoint, in aqueous solution, the enthalpy and entropy changes on formation of complexes is usually more influenced by changes in the hydration of cations and ligands (especially if the latter are anionic) than by the cation-ligand interaction itself. Complexation always results in a decrease in the hydration of the ions and of the ligands, which provides a positive entropy change, reflecting the increase in randomness of the system. In the particular case of multidentate ligands, this results in a large chelate effect. The more the ligand is pre-organized, respectively pre-disposed, the larger the chelate effect (in the case of macrocyclic ligands, one speaks of "macrocyclic effect"). The entire complexation 
process between a $\mathrm{Ln}^{3+}$ ion and a charged ligand $\mathrm{L}^{\mathrm{n}-}$ may be viewed as follows, based on the electrostatic model:

(i) Dehydration step

$$
\begin{aligned}
& {\left[\mathrm{Ln}\left(\mathrm{H}_{2} \mathrm{O}\right)_{\mathrm{x}}\right]^{3+}+\left[\mathrm{L}\left(\mathrm{H}_{2} \mathrm{O}\right)_{\mathrm{y}}\right]^{\mathrm{n}-}=\left[\mathrm{Ln}\left(\mathrm{H}_{2} \mathrm{O}\right)_{\mathrm{x}}\right]^{3+}+\left[\mathrm{L}\left(\mathrm{H}_{2} \mathrm{O}\right)_{\mathrm{y}}\right]^{\mathrm{n}-}+\left(\mathrm{x}+\mathrm{y}-\mathrm{x}^{\prime}-\mathrm{y}^{\prime}\right) \mathrm{H}_{2} \mathrm{O}} \\
& \Delta G^{d}
\end{aligned}
$$

(ii) Complexation step

$$
\begin{aligned}
& {\left[\mathrm{Ln}\left(\mathrm{H}_{2} \mathrm{O}\right)_{x^{\prime}}\right]^{3+}+\left[\mathrm{L}\left(\mathrm{H}_{2} \mathrm{O}\right)_{y^{y}}\right]^{\mathrm{n-}}=\left[\mathrm{Ln}(\mathrm{L})\left(\mathrm{H}_{2} \mathrm{O}\right)_{\left(\mathrm{x}^{\prime}+y^{\prime}\right)}\right]^{(3-\mathrm{n})+}} \\
& \Delta G^{c}
\end{aligned}
$$

Therefore, the total variation of free Gibbs energy for the reaction:

$$
\begin{aligned}
& {\left[\mathrm{Ln}\left(\mathrm{H}_{2} \mathrm{O}\right)_{\mathrm{x}}\right]^{3+}+\left[\mathrm{L}\left(\mathrm{H}_{2} \mathrm{O}\right)_{\mathrm{y}}\right]^{\mathrm{n}-}-\left[\mathrm{Ln}(\mathrm{L})\left(\mathrm{H}_{2} \mathrm{O}\right)_{\left(\mathrm{x}^{\prime}+\mathrm{y}\right)}\right]^{(3-\mathrm{n})+}+\left(\mathrm{x}+\mathrm{y}-\mathrm{x}^{\prime}-\mathrm{y}^{\prime}\right) \mathrm{H}_{2} \mathrm{O}} \\
& \Delta G^{r}
\end{aligned}
$$

can be expressed at constant pressure and temperature as:

$$
\Delta G^{r}=\Delta G^{d}+\Delta G^{c}=\Delta H^{d}+\Delta H^{c}-\mathrm{T}\left(\Delta S^{d}+\Delta S^{c}\right)
$$

Usually, there is a compensation effect, that is $\Delta H^{d} \approx-\mathrm{T} \Delta S^{d}$ so that $\Delta G^{d}$ $\approx 0$. Experimentally, $\Delta S^{r}$ is positive (especially for macrocyclic ligands), and so is very often $\Delta H^{r}$ (which means that usually, the Ln-L bonds are weaker than the $\mathrm{Ln}-\mathrm{OH}_{2}$ ones) so that complexation reactions in water are entropy driven and, moreover, a linear relationship between $\Delta H^{r}$ and $\Delta S^{r}$ holds for the $\operatorname{Ln}(\mathrm{III})$ series of cations. One has, however, to be cautious when this approach is applied to polydentate ligands. The thermodynamic parameters may also reflect other factors such as the formation of stable 5 -membered chelate rings. When another solvent is considered, the solvation enthalpy is much smaller than in water and the above considerations may no more hold.

\subsubsection{Kinetics}

Trivalent lanthanide ions are known as being kinetically very labile, with water exchange rates in the range $10^{7}-10^{9} \mathrm{~s}^{-1}$ Complexation reactions with 
non-cyclic, simple, ligands or self-assembly processes are also quite fast. In general, the reaction sequence fits within the Eigen-Tamm mechanism:

$$
\begin{gathered}
{\left[\operatorname{Ln}\left(\mathrm{H}_{2} \mathrm{O}\right)_{\mathrm{x}}\right]^{3+}+\left[\mathrm{L}\left(\mathrm{H}_{2} \mathrm{O}\right)_{\mathrm{y}}\right]^{\mathrm{n}-}=\left\{\left[\operatorname{Ln}\left(\mathrm{H}_{2} \mathrm{O}\right)_{\mathrm{x}}\right]\left[\mathrm{L}\left(\mathrm{H}_{2} \mathrm{O}\right)_{\mathrm{y}}\right]\right\}^{(3-\mathrm{n})+}=} \\
=\left[\operatorname{Ln}(\mathrm{L})\left(\mathrm{H}_{2} \mathrm{O}\right)_{\left(\mathrm{x}^{\prime}+\mathrm{y}^{\prime}\right)}\right]^{(3-\mathrm{n})+}+\left(\mathrm{x}+\mathrm{y}-\mathrm{x}^{\prime}-\mathrm{y}^{\prime}\right) \mathrm{H}_{2} \mathrm{O}
\end{gathered}
$$

The first step is diffusion-controlled and is the fastest step in the complexation process. It leads to the formation of an outer-sphere complex which, in a subsequent stage yields the inner-sphere complex. The overall rate of complex formation with simple ligands (such as $\mathrm{SO}_{4}^{2-}$ ) may be as fast as the water exchange processes. For multidentate ligands, the rate determining step is usually the ring-closure step, and the overall formation constant becomes small: for instance, the pseudo first-order rate constant for the formation of the lutetium complex with dtpa (a branched polyaminocarboxylate, diethylenetriaminepentaacetic acid) amounts to $4.6 \mathrm{mn}^{-1}$ at $\mathrm{pH} 7.8$ and $298 \mathrm{~K}$. For macrocyclic ligands, and in non-aqueous solvents, the situation may be dramatically different. For instance, the pseudo first-order rate constant at $\mathrm{pH} 7.8$ and $298 \mathrm{~K}$ for the formation of the $\mathrm{Lu}(\mathrm{III})$ complex with the tetra-anionic macrocyclic dota ligand $(1,4,7,10$-tetraazacyclododecane-1,4,7,10-tetraacetic acid) amounts to only $6.3 \times 10^{-3} \mathrm{mn}^{-1}$, which is almost three orders of magnitude smaller than with dtpa and corresponds to a half-life of $110 \mathrm{~min}$. It therefore takes several days to reach thermodynamic equilibrium under these experimental conditions. Since the metal ion competes with the proton, the reaction rate is lowered when the $\mathrm{pH}$ is decreased. Longer spans of time are needed to reach equilibrium with cryptands (up to several weeks).

\subsubsection{Synthetic Strategies}

In our case, the receptor must match the coordination number requirement of the $\mathrm{Ln}^{\mathrm{III}}$ ion (usually 8-10) and provide strong metal-ligand interactions so that the resulting edifice does not dissociate in solution. In addition, photophysical requirements discussed above must be satisfied, particularly with respect to the antenna effect and the minimization of non-radiative deexcitation. In view of the difficulty in meeting all these constraints, several 
different strategies have been tested and used. One is based on the lock and key principle and uses relatively rigid macrocyclic or macropolycyclic ligands (organized receptors). The fine-tuning of their cavity size is however very difficult to achieve, so that receptors based on the induced fit principle are more popular. These receptors are pre-disposed, that is they build a cavity upon reacting with the metal ion. Several classes of molecules can be used, large flexible macrocycles, macrocycles bearing functionalized pendant arms, or multidentate podands. Finally, self-assembly processes can also be quite successful in encapsulating a metal ion into a complex edifice. These aspects are summarized in several review articles [4,16-18].

\subsection{Biochemical Aspects}

Finally, since the luminescent probe has to be attached onto a biological molecule, it has to bear adequate coupling groups, henceforth, the designation of "bifunctional" chelates. There are many different methods to label biological material and a good insight into the problem is given by the review article of Mayer and Neuenhofer [19]. As far as luminescent lanthanide stains are concerned, one relatively simple group to introduce into bifunctional labels is isothiocyanatophenyl, which was used in the early times of heterogeneous immunoassays (1-3, Figure 3). Sometimes, however, this group is not easy to graft onto a receptor; for instance, Rodriguez-Ubis et al. report that $\mathbf{4}$ requires a tedious synthetic preparation and is very difficult to purify [20]. Other obvious groups could be carboxylic acids (see 7, Figure 3 ) or primary amines at the end of a relatively long aliphatic chain (to prevent direct interaction between the lanthanide chelate and the biological material). Good success has been met by chlorosulfonyl groups grafted on relatively complex chromophores (see 5 and $\mathbf{6}$ on Figure 3). When it comes to intercalate a reporter group into DNA strands, methylphenanthridine groups (8, Figure 3$)$ are very effective.

The following sections will essentially focus on applications of lanthanide luminescence in medical diagnosis and therapy. Another aspect of interest is the determination of intramolecular distances in macromolecules, particularly proteins, through resonant energy transfer. In this method, one analyses how the lifetime $\tau$ and emission intensity $I$ of a reporter luminescent molecule (the donor) are influenced by the presence of 
an energy acceptor; if one assumes a dipole-dipole (Förster) mechanism for the energy transfer, the distance $R_{\mathrm{DA}}$ is given by the following equation:

$$
1-\frac{\tau_{o b s}}{\tau_{0}}=\frac{I_{o b s}}{I_{0}}=\frac{1}{1+\left(R_{\mathrm{DA}} / R_{0}\right)}
$$

in which indices 0 refer to the situation where no energy transfer occurs. $R_{0}$ is the critical distance for $50 \%$ transfer; it depends on an orientation factor and on the overlap integral between the emission spectrum of the donor and the absorption spectrum of the acceptor [21]. Lanthanide-containing luminescent probes have definite advantages over organic molecules, especially because their long lifetime allows random orientation of the donor and acceptor during the energy transfer process, in addition to the advantages mentioned earlier (line-like emission lines). Distances between 20 and $100 \AA$ can be conveniently determined by this luminescent resonant energy transfer (LRET) method [22]. Many studies use thiol-reactive chelators to bind a $\mathrm{Ln}^{\mathrm{III}}$ ion at an engineered Cys residue in the macromolecule. An alternative approach has recently been proposed in which an EF-hand motif comprised of two $\alpha$-helices connected by a loop containing 12 amino acids is connected to the macromolecule. Six of the latter build a metal-binding site with high selectivity for $\mathrm{Ca}^{\mathrm{II}}$. Because of the well-known similarities between the chemical properties of $\mathrm{Ca}^{\mathrm{II}}$ and $\mathrm{Ln}^{\mathrm{III}}$, the trivalent ions are also bound selectively. This new approach has been successfully tested for the estimation of distances in a polytopic membrane transport protein, LacY [23].

To illustrate further the problematic of labelling biological material, we refer to another recent article describing the binding of a terbium dota complex to an antibody, 2D12.5 [24]. Antibodies that bind selectively lanthanide chelates under physiological conditions can find welcome applications in diagnosis (e.g. immunoassays) and therapy. In this work, dota has been derivatized in two ways (Figure $4)$ by the addition of (S)-2-(4-(2-bromo)-acetamido)-benzyl (BAD) and (S)-2-(4-nitrobenzyl) (NBD) on one of the ring methylene groups. The complex between $\mathrm{Y}^{\mathrm{III}}$ and BAD was linked to bovine serum albumin (BSA) via 2-iminothiolane and immobilized. The antibody was then incubated at $37{ }^{\circ} \mathrm{C}$ in the presence of this immobilized 
<smiles>O=C(O)CN(CC(=O)O)CC(c1ccc([N+](=O)[O-])cc1)N(CC(=O)O)C(=O)O</smiles><smiles>O=C(O)CN(CCN(CC(=O)O)CC(=O)O)CCN(CCN(CC(=O)O)CC(=O)O)Cc1ccc(N=S)cc1</smiles><smiles>O=C(O)CN1CCN(CC(=O)O)CCN(CC(=O)O)CCN(CC(=O)O)CCN(CC(=O)O)CC1</smiles><smiles></smiles>

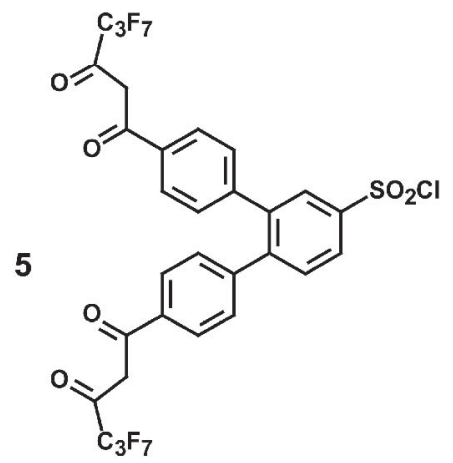<smiles>O=C(CC(=O)C(F)(F)C(F)(F)C(F)(F)C(F)(F)C(F)(F)C(F)(F)F)c1ccc2sc3ccc(S(=O)(=O)Cl)cc3c2c1</smiles><smiles>O=C(O)CN(CCN(CC(=O)O)CC(=O)Nc1ccc(C(=O)O)c(O)c1)CC(=O)O</smiles><smiles>CCc1ccc2c(c1)c1ccccc1c[n+]2C</smiles>

FIG. 3. Coupling groups used in bifunctional chelates: isothiocyanatophenyledta (1), isothiocyanatophenyl-dtpa (2) [9]; PA-dota (3) [45]; polycarboxylate diazolylpyridine ligand derivatized with an isothiocyanato phenylcarbamoyl group (4) [46]; 4,4'-bis(heptafluoro-4",6"-hexanedion-6"-yl)chlorosulfo-oterphenyl (5, BHHCT) [10]; 1,10-bis(8'-chlorosulfo-dibenzothiophene-2'-yl)octafluorodecane-1,3,8,10-tetraone (6, BCOT) [47]; p-aminosalicylate-dtpa (7, dtpa-pAS) [48]; methylphenanthridinium group for DNA intercalation 8 [49]. 
complex and of a soluble metal complex with NBD. The antibody was found to bind all the lanthanide-NBD complexes, including the $\mathrm{Y}^{\mathrm{III}}$ and ScIII ones. A plot of the dependence of the standard Gibbs free energy on the metal ionic radius can be described by a parabola and points to elastic binding behavior between $2 \mathrm{D} 12.5$ and the rare earthNBD complexes. The dissociation constant for the Y-NBD complex is $10^{-8} \mathrm{M}$ and that of the most tightly bound $\mathrm{Gd}^{\mathrm{III}}$ complex is approximately three times smaller. Time-resolved luminescence shows an improved emission of the $\mathrm{Tb}^{\mathrm{III}}$ ion when bound to the antibody.

\subsection{Methodological Aspects: Time-resolved Luminescence (TRS)}

Measurement of the $\mathrm{Ln}^{\mathrm{III}}$ luminescence is fairly straightforward, although it requires a special instrumentation. First, a UV-light pulse is shined onto the sample (the wavelength is chosen via a special filter). Then a delay is applied, to let the background fluorescence (and, possibly, short-lived phosphorescence) fade off, before starting light measurement (Figure 5). In this way, solely the $\mathrm{Ln}^{\mathrm{III}}$ luminescence is measured and signal-to-noise ratio is high. Moreover, the total length of the experiment is on the order of a few milliseconds, so that it can be repeated a few hundred times a second. In less than one minute, tens of thousand of measurements can be carried out, boosting even more the signal-to-noise ratio (which increases as the square root of the number of measurements). Sensitivities down to $10^{-13}-10^{-15} \mathrm{M}$ are easily reached.
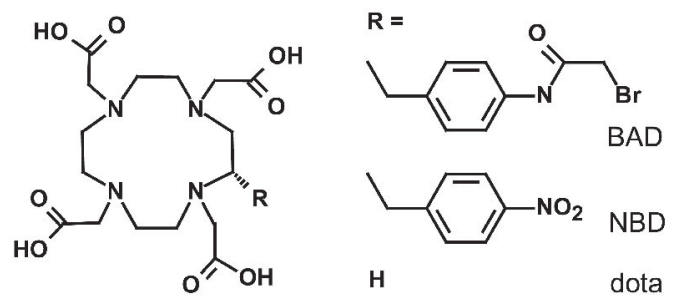

FIG. 4. Formulae of two bifunctional dota-derivatives interacting with antibody 2D12.5 [24]. 


\section{APPLICATIONS IN MEDICAL DIAGNOSIS}

\subsection{Heterogeneous versus Homogeneous Immunoassays}

Most applications in medical diagnosis make use of immunoassays detected by time-resolved luminescence. At first a two-step process was developed (Figure 6) in which a monoclonal antibody is linked to a europium chelate and let interact with the immobilized analyte (usually an hormone). After washing, the $\mathrm{pH}$ is lowered and the competition between protons and the metal ion releases the $\mathrm{Eu}^{\mathrm{III}}$ ion which is then complexed by a $\beta$-diketonate in order to trigger the antenna effect; to minimize water interaction, the new chelate is inserted into a micelle before time-resolved luminescence measurement.

The advantage of the homogeneous assays developed by Mathis [25] is their simplicity (Figure 7). The antigen to be analyzed is reacted with two specific monoclonal antibodies, one bearing a europium chelate and the other an energy acceptor emitting red light with high quantum yield. Following UV excitation of the EuIII chelate (or cryptate), energy is not emitted by the metal ion but, rather, transferred non-radiatively onto the acceptor which, in turn emits its characteristic fluorescence. Since the excited state is populated by the de-excitation of the long-lived ${ }^{5} \mathrm{D}_{0}(\mathrm{Eu})$ level, red light is emitting with a lifetime characteristic of the latter, allowing TRS detection. The energy transfer occurs within distances characteristic of antigen-antibody complexes $(7-10 \mathrm{~nm})$, but not at greater

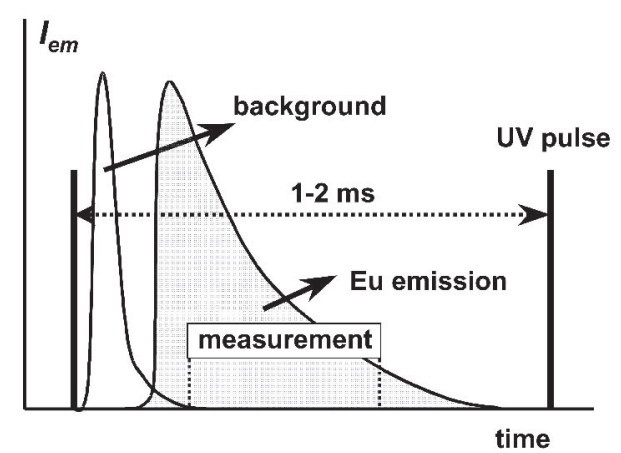

FIG. 5. Principle of time-resolved luminescence. 
distances, which makes it quite specific. This type of assay can also detect protein-protein interaction and DNA hybridization.

\subsection{Nucleic Acids and DNA Hybridization Probes}

Advances in recombinant DNA technology and sensitive methods for analyzing the organization of specific genes are major contributors to genomics. These techniques rely on nucleic acid hybridization probes for the detection of complementary nucleic acid sequences. DNA probes are more and more used in diagnostic medicine, e.g., in the recognition of genetic predisposition to a given disease, virus detection, bacterial identification or antibiotic sensitivity testing. Until the 1990's, radioisotopes (e.g., ${ }^{32} \mathrm{P},{ }^{3} \mathrm{H}$ ) were common labels for nucleic acid probes, but stability and safety problems led to search for alternative, non-isotopic stains. Truly biochemical methods were proposed, such as biotinylated nucleotide analogues detected by streptavidin or proteins crosslinked to the nucleic acid, but their sensitivity never matched the sensitivity of radio-assays, leaving an opportunity for luminescent assays.

In one of the early tests, based on heterogeneous immunoassays, DNA probes $(1.2 \mathrm{~kb}$, single stranded) were chemically modified with

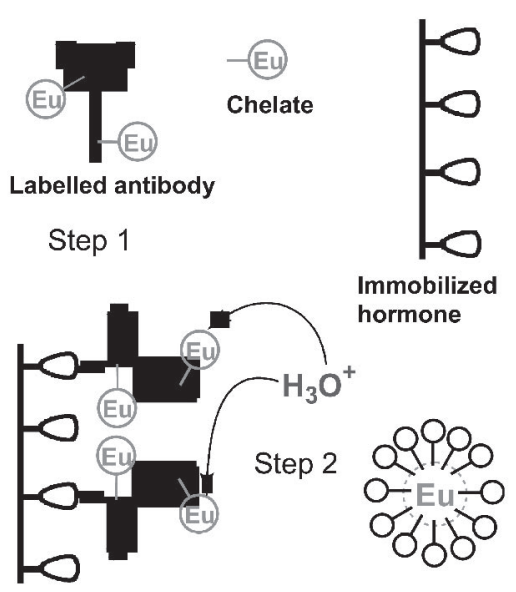

FIG. 6. Principle of a heterogeneous luminescent immunoassay. 


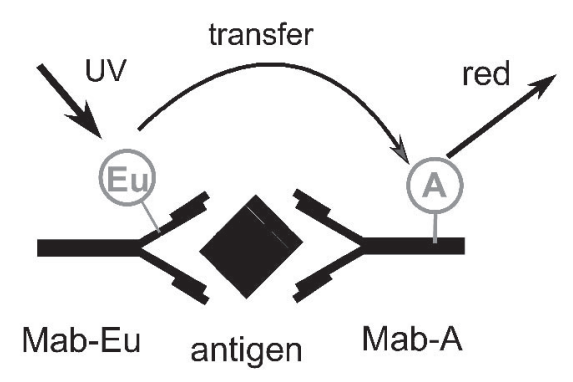

FIG. 7. Principle of a homogeneous luminescent immunoassay $(\mathrm{Mab}=$ monoclonal antibody).

immunogenic fluorine (7-iodo- $N$-acetoxy- $N$-2-acetylaminofluorene) or sulfone and, after hybridization, they were allowed to react with specific antibodies. The latter were, in turn, coupled to another antibody (anti-rabbit or anti-mouse $\mathrm{IgG}$ ), labelled with a $\mathrm{Eu}^{\mathrm{III}}$ probe. In this way, adenovirus type 2 DNA could be quantified in nasopharyngeal mucus, with a sensitivity of about $10^{7}$ genomes per test [26].

Terbium-containing labels also proved to be highly sensitive in the detection of DNA fractions during polyacrylamide gel electrophoresis. The chelating ligand is prepared by reacting diethylenetriaminetetraacetic acid monoanhydride with $p$-aminosalicylate (acting as energy donor). It is then reacted with a plasmid digest, in the presence of terbium chloride, to yield a DNA-chelate conjugate, the luminescence of which is assessed quantitatively. The DNA-chelate conjugate is very stable, even at elevated temperature $\left(60^{\circ} \mathrm{C}\right)$ and in the presence of an electric field [27]. Homogeneous essays have also been proposed, for instance by formation of ternary complexes with $\mathrm{Tb}^{\mathrm{III}}$. In an earlier example, $p$ aminosalicylate was attached to the 3 ' end of an oligonucleotide while the 5' end of another nucleotide was fitted with a $\mathrm{Tb}^{\mathrm{III}}$ chelate with dtpa. The oligonucleotide sequences were chosen so that after hybridization, the energy donor and acceptor were positioned at an ideal distance for efficient energy transfer. The sensitivity reached 1 picomole of template DNA per milliliter [28].

Detection of DNA hybridization (Figure 8) is made through resonance energy transfer, according to a principle similar to that depicted in 
Figure 7 [29]. A europium chelate functionalized with a carbostyril-124 dye (energy donor) is connected to the 5' end of a single stranded DNA. Simultaneously, the 5' end of the complementary single-stranded DNA is labelled with an energy acceptor (Cy-5, see Figure 8). When the two DNA strands interact, the $\mathrm{Eu}^{\mathrm{III}}$ ion and the acceptor are brought within suitable distance to allow a non-radiative energy transfer from the metal ion onto the organic dye. The sensitized emission of Cy-5 (having the same lifetime as $\mathrm{Eu}^{\mathrm{III}}$ ) can be measured without interference from the (weak) remaining $\mathrm{Eu}^{\mathrm{III}}$ luminescence since it occurs at a different wavelength, while its direct fluorescence can be discriminated by time-resolved measurement, ensuring high signal-to-noise ratio. A similar assay using $\mathrm{Tb}^{\mathrm{III}}$ luminescence and a rhodamine derivative as the energy acceptor has been described by the same authors.

\subsection{Clinical Examples}

A limited number of examples are described here, with the aim of showing the wide application range of the luminescence techniques for diagnosis purposes.

\subsubsection{Human Immunoglobin $I_{g} E$}

The concentration of $\mathrm{I}_{\mathrm{g}} \mathrm{E}$ is the lowest of the five immunoglobins and is closely related to several allergies and analytical methods capable of

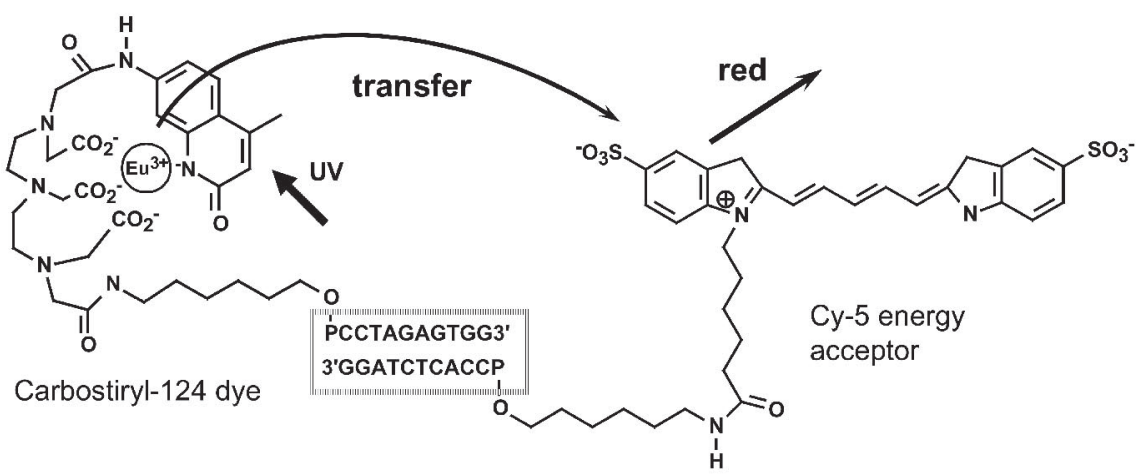

FIG. 8. Luminescence detection of DNA hybridization. Redrawn after [29]. 
measuring concentrations of $\mathrm{I}_{\mathrm{g}} \mathrm{E}$ far lower than $100 \mathrm{pg} / \mathrm{ml}$ are needed. Competitive immunoradiometric assays reach a detection limit as low as 40-300 pg/ml, but luminescence methods are much more sensitive. In the proposed assays [30], the authors use the BHHCT Eu ${ }^{\mathrm{III}}$ chelate (see Figure 3) to label streptavidin (SA) and a bovine serum albumin-streptavidin conjugate (BSA-SA). A total of 21 and 46 molecules of the Eu-chelate can be bound to SA and BSA-SA, respectively. The entire analyses are performed with 96-well microtiter plates and solid-state luminescent measurements are performed. Calibration shows that analytical recovery is better than $87 \%$ and a sensitivity of $3.6 \mathrm{pg} / \mathrm{ml}$ is achieved with a reproducibility of $7 \%$. The analysis time $(4-5 \mathrm{~h})$ is quite short compared to radioactive or enzymatic assays (several days).

\subsection{2. $\alpha$-Fetoprotein}

Human $\alpha$-fetoprotein (AFP) is one of the carcinoembryonic proteins and has been the subject of several analytical methods. Assays based on of time-resolved luminescence make use of the same Eu-chelate as previously, linked to streptavidin, SA-(BHHCT-Eu $)_{21}$. The principle is depicted in Figure 9. The wells of a microtiter plate are coated with an anti AFP monoclonal antibody and the AFP solutions are added. After incubation, successive additions of an anti AFP antibody, a biotinylated anti $\mathrm{I}_{\mathrm{g}} \mathrm{G}$ antibody, and of SA-(BHHCT-Eu) $)_{21}$ are each followed by incubation and thorough rinsing. The plate is subjected to solid-state luminescence measurement. Finally, the lanthanide label is liberated into the solution and a second luminescence measurement is performed. The sensitivity attained is impressive, $4 \times 10^{-15} \mathrm{~g} / \mathrm{ml}$, corresponding to an improvement of 4-5 orders of magnitude over the other analytical methods. The dynamic range of the method is also quite remarkable, with 6 orders of magnitude (from $10^{-4}$ to $100 \mathrm{ng} / \mathrm{ml}$ ). A similar method using the same chelating agent allows the simultaneous determination of AFP and carcinoembryonic antigen in human serum with detection limits of 0.07 and $0.3 \mathrm{ng} / \mathrm{ml}$, respectively [31]. 


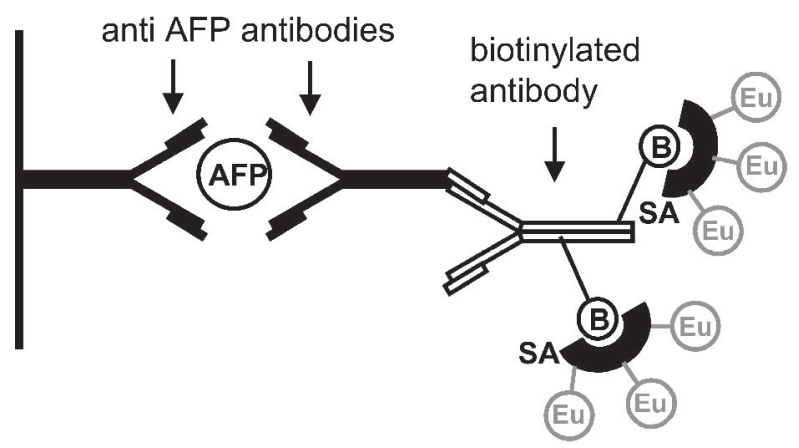

FIG. 9. Principle of the $\alpha$-fetoprotein assay (AFP; B = biotin; SA = streptavidin). Redrawn after [50].

\subsubsection{Herpes Simplex Virus}

The herpes simplex virus (HSV) can be detected in the cerebrospinal fluid, after amplification by polymerase chain reactions (PCR). The biotinylated PCR products are collected on streptavidin-coated microtitration wells and hybridiZed with short oligonucleotide probes containing a luminescent lanthanide ion: $\mathrm{Eu}^{\mathrm{III}}$ for HSV-1 and $\mathrm{Sm}{ }^{\mathrm{III}}$ for HSV-2. This method proved to be very rapid and sensitive (down to 0.1 infectious unit) [32].

\subsubsection{Prostate Specific Antigen}

Target nucleic acids can be quantified by direct hybridization assays but the high sensitivity needed in medical diagnosis often requires amplification through PCR. The number of input template molecules is calculated from the amount of PCR product and quantification is achieved by comparing the amplification signal of the sample with the amplification signal obtained from various amounts of a known standard. Homogeneous time-resolved luminescence detection is of great help in this type of analyses. In one example, Nurmi et al. propose both a competitive end-point and a real-time methods for the quantification of prostate-specific antigen (PSA) double-stranded cDNA [33]. The 
competitive assay makes use of a dual $\mathrm{Eu}^{\mathrm{III}} / \mathrm{Tb}^{\mathrm{III}}$ label while the second method is based on a single $\mathrm{Tb}^{\mathrm{III}}$ label. Results obtained from the two assays are consistent. With respect to PSA, the relevant target amounts are between $10^{2}$ and $10^{6}$ molecules, while one prostate cancer cell contains an average of $10^{3}$ PSA mRNA molecules. If 30-40 PCR cycles are used, the sensitivity of the methods is around 10-50 input molecules of PSA cDNA. Lower detection limits can be achieved by increasing the number of PCR cycles.

\subsubsection{Children Diabetes}

In type 1 diabetes, progressive destruction of insulin-producing $\beta$ cells occurs in the endocrine pancreas. Antibodies against $\beta$-cells can be detected in the serum of a prediabetic subject, indicating an ongoing autoimmune process before the diagnosis of the illness. Expression levels of mRNA specific for each cytokine have been determined in blood mononuclear cells by multiple reverse transcription PCR followed by hybridization reactions with lanthanide-labeled probes detected by TRS. This study shows that children with newly diagnosed diabetes express smaller amounts of cytokines, compared to controls [34].

\subsubsection{Determination of Grepafloxacin}

Grepafloxacin is a drug administrated to patients with urinary, respiratory or cutaneous infections; it is a synthetic fluorinated quinolone derivative having activity against gram-positive and gram-negative bacteria. Callejón and co-workers have developed an analytical method based on the luminescence of the terbium-grepafloxacin complex to quantify its concentration in human urine and serum [35]. Average recoveries were around $90 \%$ and dynamic range between 10 and $500 \mathrm{ng} / \mathrm{ml}$. It is noteworthy that this analysis is much simpler than the previously described ones in that terbium chloride is let to interact with the drug in the presence of sodium dodecylsulfate. The measurement technique (TRS) is, however, the same. 


\subsection{Imaging Techniques for Enhanced Detection of Cancerous Cells}

While magnetic resonance imaging (MRI) is a well established tool to monitor organs for carcinomas, in parallel there is a need for better methods for the in vivo analysis of specific tissues. Monitoring the fluorescence from the tissues is an appealing idea, but the signal is small and often difficult to interpret, henceforth the necessity for contrast enhancing agents, similarly to what is made in MRI. Metal chelates are candidates of choice. They must, however meet many stringent requirements, including high thermodynamic stability and suitable photophysical properties. With the knowledge acquired during the last decades, these requirements can be reasonably well fulfilled, especially if lanthanide reporters are used, in view of their specific spectroscopic advantages (line-like emission in the visible, long lifetimes).

A more difficult problem remains to be solved, namely, selectivity towards a specific tissue. One approach consisted in introducing exogenous markers similar to the drugs used in photodynamic therapy of cancer (see Section 4 below). These drugs, however, present a series of disadvantages, including their slow pharmacokinetics and light-induced toxicity. To date, the most promising approach has been pioneered by Bornhop et al. [36,37] who developed a class of terbium chelates with adequate properties from a cyclen framework fused with a pyridine ring. One of the chelating agents, termed PCTMB is depicted in Figure 10. The terbium chelate is very

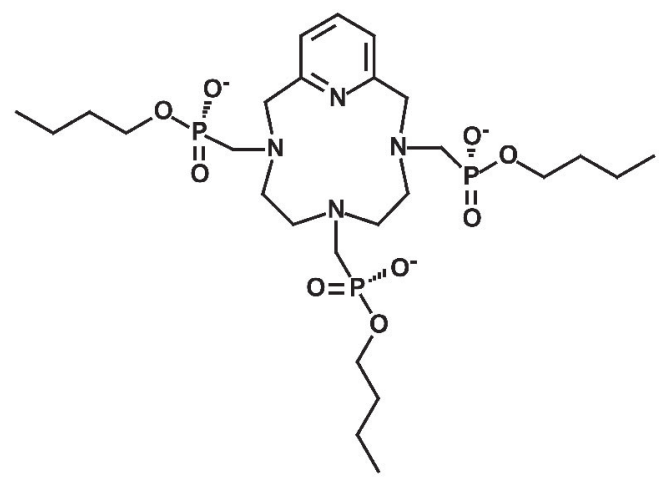

FIG. 10. Trianionic chelate (PCTMB) used in imaging of cancer cells. 
stable and, upon excitation in the UV $(270 \mathrm{~nm})$, emits a bright green light with a quantum yield of $51 \%$. One drawback is UV excitation which may damage DNA, but the light intensity needed is low enough to be below the level inducing mutageneses. The neutral overall charge of the $\mathrm{Tb}^{\mathrm{III}}$ chelate and its lipophilic nature facilitate transport in tissues. Some selectivity has been observed as well, for instance an enhanced uptake of the chelate by abnormal colon tissue. Further tests of this compound are under way.

\section{USE OF LANTHANIDE COMPLEXES IN PHOTODYNAMIC THERAPIES}

Although not based on intrinsic lanthanide luminescence, remarkable properties of some lanthanide complexes are being used in photodynamic therapy of various pathologies, so that we briefly describe these emerging applications.

\subsection{Principle of Photodynamic Therapy}

In a rare blood disease, porphyria, porphyrins accumulate in the skin, bones and teeth. Although benign in the dark, porphyrins are transformed by sunlight into flesh-eating toxins. While trying to find a treatment to cure this disease, scientists realized that porphyrins could be a tool for medicine. Metal-free porphyrins, after excitation by absorption of light, can transfer their excess energy onto dioxygen to produce highly reactive singlet oxygen, ${ }^{1} \mathrm{O}_{2}$, or free radicals. These, in turn, destroy cells. Similarly, metalloporphyrins based on metals which do not interact with the extended delocalised $\pi$-system of the porphyrin ring, lead to the same effects.

In fact, porphyrins possess another medically useful property: they accumulate in cancer cells, or more generally, in fast growing tissues, so that they are presently being explored in the context of a number of medical applications ranging from cancer therapy (the best known application), to cardiology, ophthalmology, or dermatology. Starting at the end of the 1970's, patients with breast, lung, prostate, and skin cancer have been treated by photodynamic therapy. In this cure, a porphyrin photosensitiser is administrated via intravenous injection and localizes in the cancerous 
region. Visible (red) light is used to activate the sensitiser and to produce singlet oxygen, the cytotoxic agent. Results were encouraging, with almost $100 \%$ of complete or partial response. On the other hand, secondary effects developed, such as burns and skin rashes. Moreover, the early porphyrin treatments were seldom strong enough to kill the entire tumor. Finally, some porphyrins are activated by light that cannot penetrate deep enough in the tumor. Henceforth, the search for new porphyrins with a greater potency and which could be activated by light penetrating deeper in human tissues, in the near infrared range. One category of such photosensitisers may be the texaphyrins.

\subsection{Lanthanide Texaphyrins}

At the end of the 1980's, John Sessler from the University of Texas at Austin has developed a new class of pyrrole-based expanded porphyrins that he named "texaphyrins" (Figure 11) [38].

Like the porphyrins, texaphyrins are fully aromatic and highly colored. However, they form - formally - $22 \pi$-electron systems instead of $18 \pi$-electron ones; consequently, they are dark green rather than purple with their lowest energy transition falling at $700 \mathrm{~nm}$ instead of $620 \mathrm{~nm}$ for porphyrins. Texaphyrins are monoionic ligands with a central core $20 \%$ larger than that of porphyrins and they are capable of binding a variety of metal cations, including lanthanide ions, and stabilizing a number of unusual coordination geometries. Due to their enlarged cavity with respect to porphyrins, they are ideally suited for forming very stable and highly inert complexes with lanthanide ions. The large stability of metallotexaphyrins is due to the ligand oxidation accompanying metal insertion; the macrocycle tightens up around the metal ion, preventing easy dissociation. Lanthanide complexes with several texaphyrin derivatives have been studied $\left(\mathrm{R}^{\prime}=\mathrm{H}, \mathrm{R}=\mathrm{CH}_{3}, \mathrm{OCH}_{3}, \mathrm{O}\left(\mathrm{CH}_{2}\right)_{3} \mathrm{OH}\right.$ for instance, see Figure 11). The structure of the gadolinium complex with the texaphyrin HTex 1 contains cationic species $\left[\mathrm{Gd}\left(\mathrm{NO}_{3}\right)(\mathrm{MeOH})_{2}(\mathrm{Tex} 1)\right]^{+}$ with a nine-coordinate metal ion (Figure 12); the Gd(III) ion is ligated by the five nitrogen atoms of the ligand, one bidentate nitrate ion and two molecules of methanol; it sits at approximately $0.6 \AA$ from the plane of the five nitrogen atoms. 

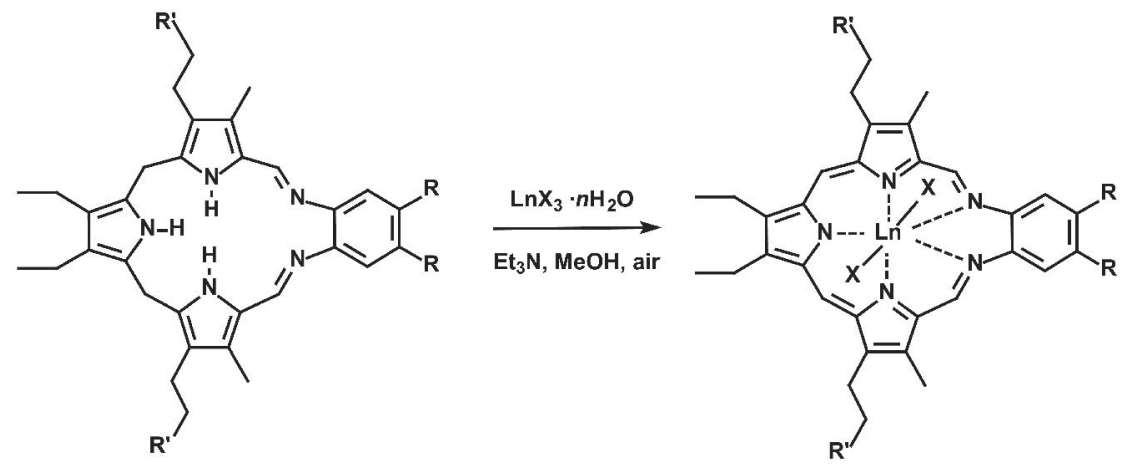

FIG. 11. Oxidative formation of a lanthanide texaphyrin complex.

Lanthanide complexes with texaphyrins are easier to reduce than typical metalloporphyrins. For example, the following potentials have been measured versus normal hydrogen electrode in dmf: $E_{1 / 2}=-0.041$ and -0.044 $\mathrm{V}$ for $\mathrm{Gd}$ and La complexes with HTex2 (Figure 13) as compared to -1.41 $\mathrm{V}$ for a $\mathrm{Zn}$ (II) octaethylporphyrinate. This fact, coupled with the observation that texaphyrins show the tumour selectivity characteristics of many porphyrins, led to testing GdTex 2 as an enhancing agent in X-ray radiation therapy. In addition, the GdTex 2 complex presents a sizable relaxivity so that it is detectable by magnetic resonance imaging techniques, allowing non-invasive evaluation of its localization in tissues (and, of course of its elimination from tissues). It has been demonstrated that this agent works particularly well in vivo and clinical tests are under way.

Another complex of Tex2 has interesting applications, LuTex2: (i) its Q-type absorption band occurs at $720 \mathrm{~nm}$, a wavelength at which most of the body tissues are transparent, (ii) the yield of the intersystem crossing process is high, and (iii) so is the yield of singlet oxygen production (up to $70 \%$ depending on the exact experimental conditions) [39]. Additionally, it has other advantages over the previous sensitizers, being a well defined, water-soluble compound, which renders its administration easy. Finally, its toxicity in absence of light is low, reflecting a rapid clearance from the tissues. This compound is present in several drugs used in different therapies. 


\subsection{Clinical Applications}

\subsubsection{Cancer Phototherapy}

The lutetium complex with Tex2 is developed for oncologic applications under the trade name LUTRIN ${ }^{\circledR}$ by Pharmacyclics Inc. A study (phase I human clinical trial) was completed in 1997 on 35 patients with incurable cutaneous malignancies, including 15 recurrent breast cancers. After intravenous injection of the photosensitizer, they were irradiated by 732-nm light. Out of the 176 lesions examined, $28 \%$ regressed completely

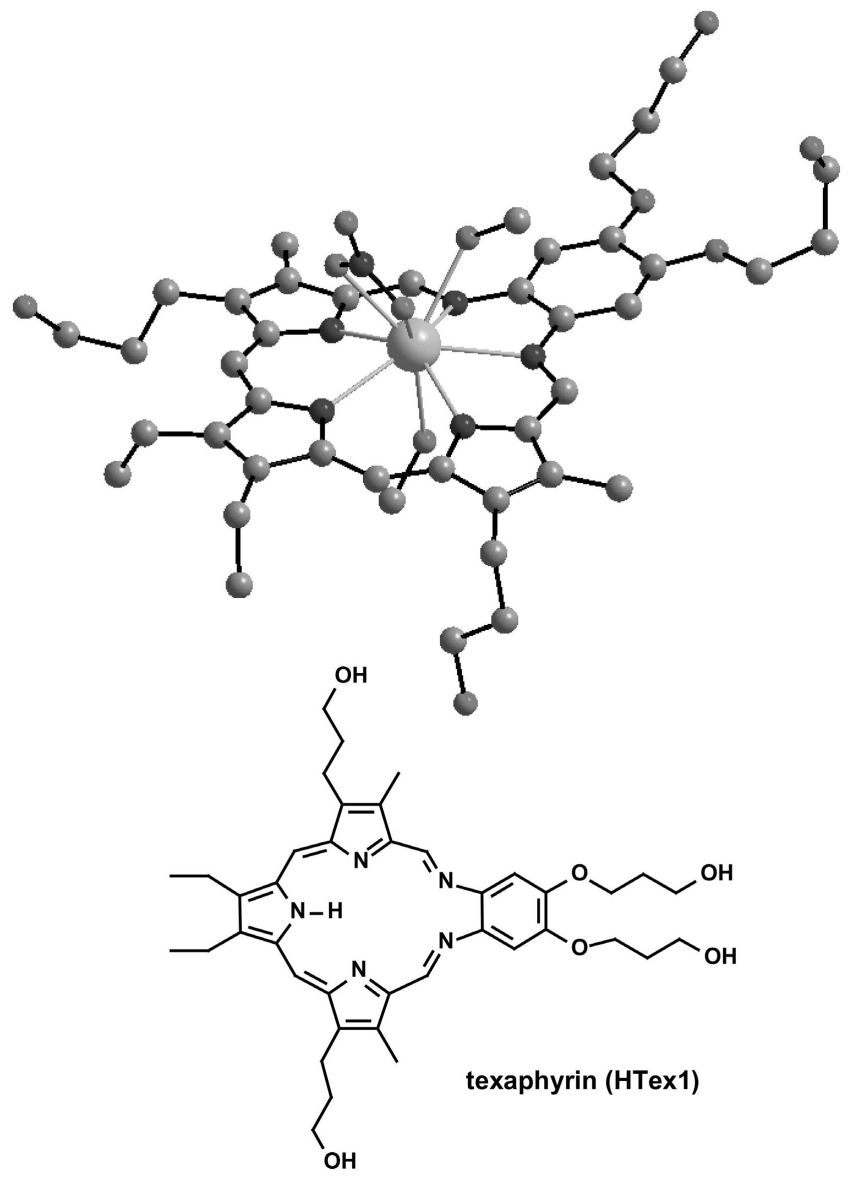

FIG. 12. Structure of $\left[\mathrm{Gd}\left(\mathrm{NO}_{3}\right)(\mathrm{MeOH})_{2}(\mathrm{Tex} 1)\right]^{+}$, redrawn from [51]. 


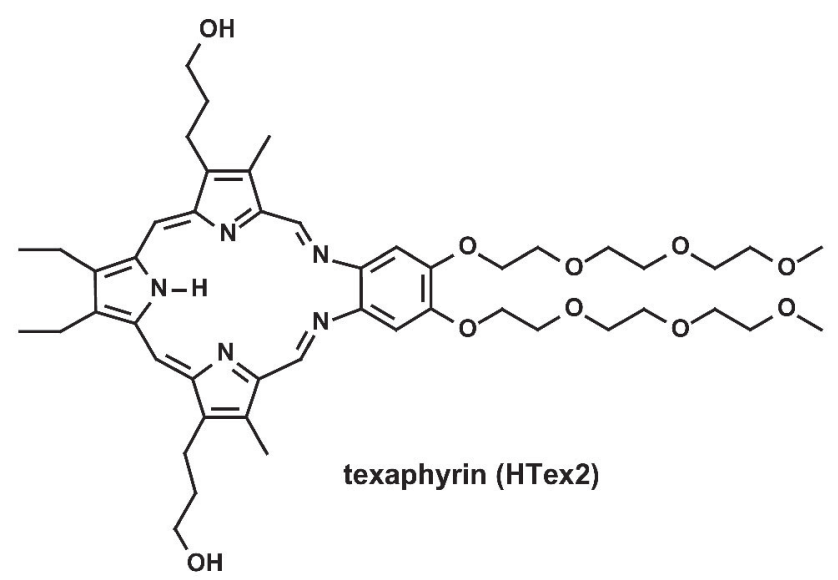

FIG. 13. Developed formula of HTex2.

and $20 \%$ partially (i.e., decreasing in size by at least $50 \%$ ). The response was quite better for recurrent breast cancers ( $45 \%$ and $18 \%$, respectively), so that a phase II clinical trial, completed in 1999, concerned solely patients with locally recurrent breast cancer. Tumor response was observed in $62 \%$ of the 52 patients involved. Assessment following treatment indicated that the lesions were no more detectable in $20 \%$ of the cases while $22 \%$ had undergone sizeable reductions $[38,40]$.

The chest wall has a large area $\left(240 \mathrm{~cm}^{2}\right)$ and several parameters have to be adjusted carefully, which, in parallel with clinical trials, generates a wealth of preclinical developments, both with respect to the irradiation conditions [41], to the elucidation of the mechanism of action of LUTRIN ${ }^{\circledR}$ [42], and to the understanding of its biolocalization properties.

\subsubsection{Photoangioplasty}

A few years ago, Woodburn and coworkers explored the possibility of using a lutetium complex with texaphyrin Tex2 (under the trade name ANTRIN $^{\circledR}$ ) in the removal of atheromatous plaque [43]. Atherosclerotic vascular disease is indeed one of the leading cause of death in the Western world. The fact that porphyrin-like macrocycles are taken up more in 
atheromatous plaque than in the walls of normal vessels motivated this development. In a phase I clinical trial, the drug was administrated intravenously; then a 24-h delay was applied in order to maximize the uptake of ANTRIN ${ }^{\circledR}$ in the plaque, while maximizing the clearance from plasma. Finally, 732-nm light was shined through an intravascular fiberoptic catheter. The trial revealed a safe, well-tolerated treatment without adverse vascular responses for patients with non-critical arteriosclerosis; in particular, one patient showed a nearly $50 \%$ improvement in luminal diameter $[38,40]$. Presently, Woodburn envisages extension of this therapy to graft coronary artery disease which limits patient survival following heart transplantation.

\subsubsection{Age-Related Macular Degeneration}

Almost one quarter of the people over the age of 65 suffer from macular degeneration, which is the major cause of blindness in the elderly people, particularly its wet form. Another form of $\mathrm{Lu}(\mathrm{Tex} 2), \mathrm{OPTRIN}^{\circledR}$ is in phase II clinical trial for treating this disease, after a successful preclinical test on New Zealand white rabbits [44]. The clinical study points to the texaphyrin drug localizing selectively in the choroidal neovascularization. Depending on the dose of drug and light, as well as on the interval between them, complete or partial closure of diseased vessels is achieved. In a preliminary analysis of the patients with complete or partial closure, visual acuity was found to increase substantially.

\section{CONCLUDING REMARK}

In this short review, the emphasis was put on the basic principles pertaining to the design of efficient luminescent lanthanide-containing labels for medical diagnosis and therapy. Various applications have been mentioned which demonstrate that the unique spectroscopic properties of the lanthanide ions, coupled with their peculiar chemical properties, can be taken advantage of to develop extremely sensitive analytical methods in the field of biology, medicine and pharmacy. These methods are already largely in use in most hospitals and associated laboratories. Their sensitivity being better compared to analytical methods based on radio- 
active labels, there is no doubt that they are promised to a bright future, especially with the growing interest for genomics and high throughput screening. Their applications seem only limited by the imagination of the scientists and medical doctors. On a more historical viewpoint, it is amusing that the initial thrust for the development of time-resolved luminescence analyses for biomedical purposes and based on lanthanide-containing labels came from the very university (Turku, Finland) where Johan Gadolin discovered the first rare-earth element, yttrium, in 1794 (at that time the city was Swedish-ruled and named Åbo).

\section{ACKNOWLEDGMENT}

The author is indebted to the Swiss National Science Foundation and the Swiss Federal Office for Education and Science (COST Action D18: Lanthanide chelates for diagnosis and therapy) for financial support.

\section{ABBREVIATIONS}

$\begin{array}{ll}\text { AFP } & \alpha \text {-fetoprotein } \\ \text { BAD } & (S) \text {-2-(4-(2-bromo)-acetymido)benzyl } \\ \text { BCOT } & \begin{array}{l}1,10 \text {-bis(8'-chlorosulfo-dibenzothiophene-2'-yl)- } \\ \text { octafluorodecane-1,3,8,10-tetraone }\end{array} \\ & \begin{array}{l}4,4 \text { '-bis(heptafluoro-4',6'-hexanedion-6'-yl)- } \\ \text { chlorosulfo-o-terphenyl }\end{array} \\ \text { BHHCT } & \text { bovine serum albumin } \\ & \text { cyanine dye } 5 \\ \text { BSA } & \text { dimethylformamide } \\ \text { Cy5 } & 1,4,7,10 \text {-tetraazacyclododecane-1,4,7,10-tetraacetic } \\ \text { dmf } & \text { acid } \\ \text { dota } & \text { diethylenetriaminepentaacetic acid } \\ \text { dtpa } & \text { ethylenediamine- } N, N, N \text {,'N'-tetraacetic acid } \\ \text { edta } & \text { fluoroimmunoassay } \\ \text { FIA } & \text { herpes simplex virus } \\ \text { HSV } & \text { immunoglobulin }\end{array}$




$\begin{array}{ll}\text { LMCT } & \text { ligand-to-metal charge transfer } \\ \text { LRET } & \text { luminescent resonant energy transfer } \\ \text { Mab } & \text { monoclonal antibody } \\ \text { MLCT } & \text { metal-to-ligand charge transfer } \\ \text { MRI } & \text { magnetic resonance imaging } \\ \text { NBD } & (S) \text {-2-(4-nitrobenzyl) } \\ \text { pAS } & \text {-aminosalicylate } \\ \text { PCR } & \text { polymerase chain reaction } \\ \text { PET } & \text { photo-induced electron transfer } \\ \text { PSA } & \text { prostate-specific antigen } \\ \text { SA } & \text { streptavidin } \\ \text { Tex } & \text { texaphyrin } \\ \text { TRS } & \text { time-resolved luminescence }\end{array}$

\section{REFERENCES}

1. L. Helm, E. Tóth, and A. E. Merbach, in Metal Ions in Biological Systems (A. Sigel and H. Sigel, eds.), Marcel Dekker Inc., New York, Vol. 40, 2003, pp.589-641.

2. S. I. Weissman, J. Chem. Phys., 1942, 10, 214.

3. J.-C. G. Bünzli, in Rare Earths, (R. Saez Puche and P. Caro, eds.), Editorial Complutense, Madrid, 1998, p.223.

4. J.-C. G. Bünzli, N. André, M. Elhabiri, G. Muller, and C. Piguet, J. Alloys Comp., 303/304, 66 (2000).

5. G. A. Crosby, R. E. Whan, and R. M. Alire, J. Chem. Phys., 34, 743 (1961).

6. R. A. Bulman, in Metal Ions in Biological Systems (A. Sigel and H. Sigel, eds.), Marcel Dekker Inc.: New York, Vol. 40, 683-706 (2003).

7. C. Turro, P. K.-L. Fu, and P. M. Bradley, in Metal Ions in Biological Systems (A. Sigel and H. Sigel, eds.), Marcel Dekker Inc.: New York, 2003, Vol. 40, 323-353.

8. R. K. O. Sigel and A. M. Pyle, in Metal Ions in Biological Systems, (A. Sigel and H. Sigel, eds.), Marcel Dekker Inc.: New York, 2003, Vol. 40, 477-512.

9. I. Hemmilä, T. Ståhlberg, and P. Mottram, Bioanalytical Applications of Labelling Technologies, Wallac Oy, Turku, 1995. 
10. K. Matsumoto, T. Nojima, H. Sano, and K. Majima, Macromol. Symp., 186, 117 (2002).

11. D. Parker, Coord. Chem. Rev., 2000, 205, 109.

12. M. Latva, H. Takalo, V. M. Mukkala, C. Matachescu, J.-C. RodriguezUbis, and J. Kankare, J. Lumin., 75, 149 (1997).

13. F. J. Steemers, W. Verboom, D. N. Reinhoudt, E. B. Vandertol, and J. W. Verhoeven, J. Am. Chem. Soc., 117, 9408 (1995).

14. J.-C. G. Bünzli, in Spectroscopic Properties of Rare Earths in Optical Materials (G. K.Liu and B.Jacquier, eds.), Springer Verlag, Berlin, 2003, Ch. 11, in press.

15. A. P. De Silva, H. Q. N. Gunaratne, T. Gunnlaugsson, A. J. M. Huxley, C. P. McCoy, J. T. Rademacher, and T. E. Rice, Chem. Rev., 97, 1515 (1997).

16. J.-C. G. Bünzli, in Rare Earths (B. Sastri, ed.), Elsevier Science B.V., Amsterdam, 2003 Ch. 4B, in press.

17. J.-C. G. Bünzli and C. Piguet, Chem. Rev., 102, 1897 (2002).

18. C. Piguet and J.-C. G. Bünzli, Chem. Soc. Rev., 28, 347 (1999).

19. A. Mayer and S. Neuenhofer, Angew. Chem. Intl. Ed. Eng., 33, 1044 (1994).

20. M. T. Alonso, E. Brunet, O. Juanes, and J.-C. Rodriguez-Ubis, J. Photochem. Photobiol. A-Chem., 147, 113 (2002).

21. J.-C. G. Bünzli, in Lanthanide Probes in Life, Chemical and Earth Sciences. Theory and Practice (J.-C. G. Bünzli and G. R. Choppin, eds.), Elsevier Science Publ. B.V., Amsterdam, 1989, Ch. 7, p.219ff.

22. A. Cha, G. E. Snyder, P. R. Selvin, and F. Bezanilla, Nature (London), 402, 809 (1999).

23. J. L. Vazquez-Ibar, A. B. Weinglass, and H. R. Kaback, Proc. Natl. Acad. Sci. USA, 99, 3487 (2002).

24. T. M. Corneillie, P. A. Whetstone, A. J. Fisher, and C. F. Meares, J. Am. Chem. Soc., 2003, Published on the web, February 28, 2003; DOI $10.1021 / \mathrm{ja} 029363 \mathrm{k}$.

25. G. Mathis, in Rare Earths (R. Saez Puche and P. Caro, eds.), Editorial Complutense, Madrid, 1998, p.285ff.

26. A.-C. Syvaenen, P. Tchen, M. Ranki, and H. Soederlund, Nucl. Acid Res., 14, 1017 (1986).

27. S. S. Saavedra and E. G. Picozza, Analyst, 114, 835 (1989).

28. A. Oser and G. Valet, Angew. Chem. Intl. Ed. Engl., 29, 1167 (1990). 
29. P. R. Selvin, T. M. Rana, and J. E. Hearst, J. Am. Chem. Soc., 116, 6029 (1994).

30. J. L. Yuan, G. L. Wang, H. Kimura, and K. Matsumoto, Anal. Biochem., 254, 283 (1997).

31. K. Matsumoto, J. G. Yuan, G. L. Wang, and H. Kimura, Anal. Biochem., 276, 81 (1999).

32. V. Hukkanen, T. Rehn, R. Kajander, M. Sjoroos, and M. Waris, J. Clin. Microbiol., 38, 3214 (2000).

33. J. Nurmi, H. Lilja, and A. Ylikoski, Luminescence, 15, 381 (2000).

34. M. Halminen, O. Simell, M. Knip, and J. Ilonen, Scand. J. Immun., 53, 510 (2001).

35. J. A. Ocana, M. Callejón, and F. J.Barragan, J. Pharm. Sci., 90, 1553 (2001).

36. D. J. Bornhop, D. S. Hubbard, M. P. Houlne, C. Adair, G. E. Kiefer, B. C. Pence, and D. L. Morgan, Anal. Chem., 71, 2607 (1999).

37. G. E. Kiefer, L. Jackson, and D. J. Bornhop, US Patent 5,928,627, 1999.

38. T. D. Mody, L. Fu, and J. L. Sessler, Progr. Inorg. Chem., 49, 551 (2001).

39. T. D. Mody and J. L. Sessler, J. Porphyr. Phthalocyan., 5, 134 (2001).

40. J. L. Sessler, N. A. Tvermoes, D. M. Guldi, and T. D. Mody, J. Porphyr. Phthalocyan., 5, 593 (2001).

41. A. Dimofte, T. C. Zhu, S. M. Hahn, and R. A. Lustig, Lasers in Surgery and Medicine, 31, 305 (2002).

42. K. W. Woodburn, Q. Fan, D. Kessel, Y. Luo, and S. W. Young, J. Invest. Dermatol., 110, 746 (1998).

43. K. W. Woodburn, Q. Fan, P. Thiemann, and D. Kessel, Circulation, 98, 334 (1998).

44. M. S. Blumenkranz, K. W. Woodburn, F. Qing, S. Verdooner, D. Kessel, and R. Miller, Am. J. Ophthalm., 129, 353 (2000).

45. L. L. Chappell, B. E. Rogers, M. B. Khazaeli, M. S. Mayo, D. J. Buchsbaum, and M. W. Brechbiel, Bioorg. Med. Chem., 7, 2313 (1999).

46. E. Brunet, O. Juanes, R. Sedano, and J.-C. Rodriguez-Ubis, Photochem. Photobiol. Sci., 1, 613 (2002).

47. J. L. Yuan and K. Matsumoto, J. Pharm. Biomed. Anal., 15, 1397 (1997). 
48. H. H. Shi and Y. S. Yang, J. Alloys Comp., 207, 29 (1994).

49. G. Bobba, S. D. Kean, D. Parker, A. Beeby, and G. Baker, J. Chem. Soc., Perkin Trans. 2, 1738 (2001).

50. J. L. Yuan, K. Matsumoto, and H. Kimura, Anal. Chem., 70, 596 (1998).

51. J. L. Sessler, T. D. Mody, G. W. Hemmi, and V. Lynch, Inorg. Chem., 32, 3175 (1993). 
